\title{
Сравнительная характеристика содержательных элементов экономического анализа и бизнес-анализа
}

\author{
Н. В. Кондрашова ${ }^{1 凶}$ \\ ${ }^{1}$ Воронежский государственный университет, Университетская пл., 1, \\ 394018, Воронеж, Российская Федерация
}

Для цитирования: Кондрашова Н. В. Сравнительная характеристика содержательных элементов экономического анализа и бизнес-анализа // Вестник Воронежского государственного университета. Серия: Экономика и управление. 2020. № 2. С. 45-54. DOI: 10.17308/econ.2020.2/2900

\begin{abstract}
Предмет. Особенностью современного экономического анализа является существенное изменение его задач и функций. Это обусловлено следующими причинами: преобразования в хозяйственном механизме организаций; многообразие видов деятельности определяет выделение и развитие тематических направлений экономического анализа; интеграция с другими направлениями функционирования экономических субъектов; вопросы междисциплинарности. В последние годы активное развитие получил, например, бизнес-анализ. Перечисленные причины приводят к развитию методологии экономического анализа. Теория и практика экономического анализа пополняются его направлениями, формами, методиками, способами и приемами; расширяются области практического применения экономического анализа.

Цели. Авторское исследование содержания элементов структуры экономического анализа и бизнесанализа: цель, предмет, субъекты и объекты, инструментарий; их сопоставление для определения общих или различных черт. Вопросы возможности и целесообразности стандартизации анализа как процесса научного познания; как практических процедур непосредственно анализа хозяйственной деятельности организации; требований к уровню компетенций в профессиональных стандартах.

Методология. В процессе достижения поставленных целей использовались методы научного познания: диалектический; анализа и синтеза. Исследование построено на изучении актуальной научной и периодической экономической литературы.

Выводы. Сделан вывод о понимании бизнес-анализа как отдельного тематического направления экономического анализа и, соответственно, вида аналитической работы. Специфика бизнес-анализа в итоге определяется объектом, на который направлена его практическая деятельность. Бизнес выступает объектом экономического анализа, а сам бизнес-анализ становится тематическим направлением экономического анализа. Наиболее значимой отличительной чертой бизнес-анализа от традиционных подходов в экономическом анализе следует считать лишь изменение базы сравнения - требования стейкхолдеров.
\end{abstract}

Ключевые слова: методология, направления развития экономического анализа, содержание методологических характеристик, бизнес-анализ.

\section{Введение}

Вопросы развития методологии экономического анализа хозяйственной деятельности на каждом конкретном этапе развития рыночных отношений особенно актуальны. «Совершенствование теоретических положений экономического анализа является насущной потребностью сегодняшних условий ведения бизнеса, когда все большее внимание со стороны различных заинтересованных лиц уделяется анализу результативности деятельности организаций», - пишет, например, Н. С. Пласко-

(C) Кондрашова Н. В., 2020

Вестник ВГУ. Серия: Экономика и управление. 2020. № 2. С. 45-54. ва [18]. Большинство видных ученых-аналитиков подчеркивают особенность современного экономического анализа в существенном изменении его задач и функций.

Как указывает А.Д. Шеремет, «... сейчас мы входим в четвертый этап развития анализа хозяйственной деятельности - экономико-социально-экологического анализа показателей устойчивого развития предприятия» [19]. По мнению автора, это вызовет совершенствование методов комплексного экономического анализа показателей устойчивого развития и выразится в разработке системы социальных и эко- 
логических показателей; создании системы методов анализа обратного влияния финансово-экономических показателей на экологические и социальные показатели; решении задачи комплексной оценки показателей устойчивости развития предприятия [там же, с. 6-7].

По мнению Д. А. Ендовицкого, Н. П. Любушина, Н. Э. Бабичевой [11, с. 9], экономический анализ уделял значительное внимание изучению вопросов поиска внутрихозяйственных резервов, анализу организационно-технического уровня производства. Авторы полагают, что исследования указанных и других актуальных вопросов экономического анализа будут активизированы. Ими разработано такое направление экономического анализа, как ресурсо-ориентированный [12], создана единая методология ресурсо-ориентированного экономического анализа развития организации через обоснование взаимосвязи эффективности использования ресурсов с типом развития производства, видом финансовой устойчивости, этапом жизненного цикла на стадии «производство», уровнем риска.

Как указывает Н. П. Любушин [11, с. 10; 12 , с. 3] со ссылкой на С. Б. Барнгольц и М. В. Мельник, «экономический анализ как самостоятельная область знаний тесно интегрирует с другими направлениями функционирования экономических субъектов хозяйствования - управлением, информационным обеспечением, бухгалтерским учетом, организацией производства, научно-техническим развитием и т. П. Это определяет выделение тематических направлений экономического анализа как самостоятельных направлений: финансовый и управленческий анализ, инвестиционный и инновационный анализ, в результате формируются самостоятельные разделы экономического анализа...» [6, с. 21]. Поддерживая эту точку зрения, Н. С. Пласкова высказывается: «Методология экономического анализа, являющегося одним из прикладных направлений экономической науки, находится в непосредственной зависимости от уровня развития макро-, мезо- и микроэкономики, форм собственности, полноты и качества информационного обеспечения» [18].

В последние годы достаточно большое количество работ, как научного, так и учебного характера, посвящено так называемому бизнес-анализу - сравнительно новому для отечественных экономистов направлению аналитической работы. Этот вид анализа выделяется как самостоятельное научное направление и требует, соответственно, достаточно серьёзного продумывания и пояснений. Например, В. И. Бариленко активно развивает методологические положения бизнес-анализа, считая наиболее актуальным данный вид аналитической работы в настоящих условиях развития рыночных отношений.Действительно, в нашей стране этот вид анализа приобретает все большую актуальность и популярность [2-5].

Проработав литературные источники, можно сделать вывод, что преобразования в хозяйственном механизме деятельности организаций вызывают трансформацию теоретических положений экономического анализа; его тематических направлений, видов, форм, наполнения методиками, способами и приемами; расширяются области практического применения экономического анализа.

Для автора статьи представляют интерес размышления на тему сравнительной характеристики методологического содержания элементов экономического анализа и бизнес-анализа. Цель изучения и сравнения сути и содержания этих характеристик состоит в понимании вопроса, что есть бизнес-анализ: отдельное научное направление или отдельное тематическое направление (вид) экономического анализа и, соответственно, аналитической работы? Достижение поставленной цели автор видит в решении задач: 1) провести сравнительную характеристику содержания элементов структуры экономического анализа и бизнес-анализа: цель, предмет, субъекты и объекты, инструментарий; 2) затронуть вопрос возможности и целесообразности стандартизации анализа как процесса научного познания и как непосредственно анализа хозяйственной деятельности организации.

\section{Материалы и методы исследования}

Любая наука, в том числе и экономический анализ, имеет набор отличительных методологических структурных элементов, определяющих ее суть. Согласно работам А. И. Алексеевой [1], В. Н. Михеева и И. Г. Бондаренко [16] логическая структура научной и практической деятельности любой науки состоит из ее объекта, субъекта, предмета, средства. Решая задачу понимания бизнес-анализа либо как отдельное научное направление, либо как тематическое направление экономического анализа, сопоставим характеристики элементов их структуры (табл. 1). 
Содержательные элементы экономического анализа и бизнес-анализа

\begin{tabular}{|c|c|c|}
\hline Элемент анализа & Экономический анализ & Бизнес-анализ \\
\hline Определение & $\begin{array}{l}\text { Научная и практическая де- } \\
\text { ятельность по разработке и } \\
\text { совершенствованию методов } \\
\text { и методик экономического } \\
\text { анализа, а также применению } \\
\text { их для повышения обосно- } \\
\text { ванности и эффективности } \\
\text { управления организацией [1] }\end{array}$ & $\begin{array}{l}\text { Деятельность, которая позволяет внедрять изменения } \\
\text { в компании путем определения потребностей и реко- } \\
\text { мендации решений, которые обеспечивают ценность } \\
\text { для заинтересованных лиц (свод знаний по бизнес- } \\
\text { анализу (Business analysis body of knowledge - BABOK): } \\
\text { разработан Mеждународным институтом бизнес-ана- } \\
\text { лиза (International institute of business analysis - IIBA)) }\end{array}$ \\
\hline $\begin{array}{l}\text { Целевая направ- } \\
\text { ленность }\end{array}$ & $\begin{array}{l}\text { Повышение эффективности } \\
\text { функционирования хозяй- } \\
\text { ствующих субъектов и поиск } \\
\text { резервов такого повышения }\end{array}$ & $\begin{array}{l}\text { Информационное обеспечение эффективного корпо- } \\
\text { ративного управления, которое понимается как систе- } \\
\text { ма взаимодействия между акционерами и менеджмен- } \\
\text { том компании, а также с другими заинтересованными } \\
\text { сторонами с целью реализации интересов собственни- } \\
\text { ков и законных прав остальных стейкхолдеров [17] }\end{array}$ \\
\hline Пред & $\begin{array}{l}\text { Причинно-следственные } \\
\text { связи экономических про- } \\
\text { цессов и явлений [1] }\end{array}$ & \begin{tabular}{|l|} 
Экономические явления, происходящие в результате \\
осуществления как отдельных бизнес-процессов, так \\
и всей деятельности бизнес-единиц и коммерческих \\
компаний в целом, причинно-следственные связи \\
этих явлений и процессов, а также их соответствие \\
требованиям стейкхолдеров [17]
\end{tabular} \\
\hline Объ & $\begin{array}{l}\text { Хозяйствующие субъекты, } \\
\text { хозяйственные процессы, } \\
\text { экономические результаты } \\
\text { их деятельности [1] } \\
\end{array}$ & $\begin{array}{l}\text { Бизнес-процессы, бизнес-единицы, бизнес-модели } \\
\text { коммерческих компаний, показатели их деятельно- } \\
\text { сти, требования стейкхолдеров и внешняя среда [17] }\end{array}$ \\
\hline Субъект & Пользователи информации & $\begin{array}{l}\text { Стейкхолдеры (заинтересованные лица, заинтересо- } \\
\text { ванные стороны) }\end{array}$ \\
\hline Метод & $\begin{array}{l}\text { Способ (прием) изучения } \\
\text { хозяйственных процессов в } \\
\text { их становлении и развитии }\end{array}$ & $\begin{array}{l}\text { Сравнительное изучение требований ключевых стейк- } \\
\text { холдеров коммерческих компаний и соответствующих } \\
\text { фактических параметров деятельности этих компаний, } \\
\text { выявление на этой основе проблем бизнеса и обосно-- } \\
\text { вание путей решения этих проблем [17] }\end{array}$ \\
\hline
\end{tabular}

Несмотря на неоднозначность формулировок, представленных в табл. 1 , говорить о концептуальных отличиях бизнес-анализа от экономического анализа не приходится. Остановимся, для примера, более детально на характеристике одного из элементов.

Субъект анализа. В понимании экономического анализа субъектами анализа являются пользователи информации, тогда как бизнес-анализ определяет их как стейкхолдеров. Здесь необходимо пояснить широко применяемое в бизнес-анализе понятие «стейкхолдер». Буквальное значение этого слова происходит от английского stakeholder - владелец доли, держатель заклада, дольщик и в узком смысле означает то же, что и shareholder - владелец доли в акционерном капитале, акционер, участник. Но в контексте бизнес-анализа самое распространенное определение данного понятия состоит в том, что стейкхолдеры это группы, организации или индивидуумы, на которые влияет компания и от которых она зависит [2-4; 9]. Каждый субъект анализа изучает информацию, исходя из своих интересов (табл. 2).

Бизнес-анализ подчеркивает, что у каждого стейкхолдера имеются собственные потребности и интересы, часто не совпадающие с потребностями и интересами других стейкхолдеров. Однако и экономический анализ не отрицает разницу и противоположность интересов пользователей. Причем как экономический анализ, так и бизнес-анализ разделяет пользователей анализа / стейкхолдеров на группы по ряду признаков (табл. 3).

Следует отметить, что в научной литературе уделяется значительное внимание вопросу идентификации стейкхолдеров в разрезе трактовки понятия «стейкхолдеры», а также состава лиц, которых можно ассоциировать с данным понятием. В этом смысле интересна работа Д. А. Дуденкова, где автор, 
Субъекты анализа и их интересы

\begin{tabular}{|c|c|c|}
\hline \multirow{2}{*}{ Субъекты } & \multicolumn{2}{|r|}{ Интересы } \\
\hline & Экономический анализ & Бизнес-анализ [2] \\
\hline $\begin{array}{l}\text { Собственники } \\
\text { (инвесторы) }\end{array}$ & $\begin{array}{l}\text { Оценка адекватности дохода; сте- } \\
\text { пень рискованности сделанных } \\
\text { инвестиций; оценка перспектив } \\
\text { выплаты дивидендов }\end{array}$ & $\begin{array}{l}\text { Повышение прибыли и рыночной стоимости } \\
\text { компании, обеспечивающие увеличение раз- } \\
\text { меров дивидендов и рост стоимости акций; } \\
\text { минимизация рисков вложений и максимиза- } \\
\text { ции доходности этих вложений }\end{array}$ \\
\hline Кредиторы & $\begin{array}{l}\text { Определение наличия ресурсов } \\
\text { для платы за кредит и возврата } \\
\text { кредита в срок }\end{array}$ & $\begin{array}{l}\text { Привлечение компанией возможно больших } \\
\text { сумм кредитов на выгодных для банков ус- } \\
\text { ловиях при сохранении способности своев- } \\
\text { ременно погашать ссудную задолженность и } \\
\text { уплачивать причитающиеся проценты }\end{array}$ \\
\hline Поставщики & $\begin{array}{l}\text { Положение на рынке - определе- } \\
\text { ние наличия ресурсов для оплаты } \\
\text { поставок }\end{array}$ & $\begin{array}{l}\text { Стабильность заказов, своевременность оплаты } \\
\text { поставок по возможно более высоким ценам }\end{array}$ \\
\hline Покупатели & $\begin{array}{l}\text { Положение на рынке - насколько } \\
\text { долго организация сможет про- } \\
\text { должать свою деятельность } \\
\end{array}$ & $\begin{array}{l}\text { Своевременные поставки товаров или услуг } \\
\text { требуемого качества по приемлемым ценам }\end{array}$ \\
\hline Конкуренты & $\begin{array}{l}\text { Положение на рынке - оценка } \\
\text { конкурентных преимуществ }\end{array}$ & - \\
\hline $\begin{array}{l}\text { Налоговые ор- } \\
\text { ганы }\end{array}$ & $\begin{array}{l}\text { Уплата налогов в полном объеме и } \\
\text { в установленный срок }\end{array}$ & Своевременные выплаты сумм налогов \\
\hline $\begin{array}{l}\text { Местное сооб- } \\
\text { щество и обще- } \\
\text { ственные орга- } \\
\text { низации }\end{array}$ & $\begin{array}{l}\text { Проверка выполнения требований } \\
\text { законодательства в областях, от- } \\
\text { носящихся к их компетенции }\end{array}$ & $\begin{array}{l}\text { Обеспечение занятости населения, соответ- } \\
\text { ствие деятельности требованиям законодатель- } \\
\text { ства, участие в решении социальных проблем } \\
\text { региона и вклада в его экономический рост }\end{array}$ \\
\hline $\begin{array}{l}\text { Администрация / } \\
\text { менеджеры }\end{array}$ & Все аспекты деятельности & $\begin{array}{l}\text { Результаты деятельности, находящиеся в сфе- } \\
\text { ре их ответственности }\end{array}$ \\
\hline Персонал & $\begin{array}{l}\text { Занятость, оплата труда, премии, } \\
\text { социальные выплаты }\end{array}$ & $\begin{array}{l}\text { Обеспечение гарантий занятости, достойной } \\
\text { заработной платы, улучшение условий труда, } \\
\text { удовлетворение работой, возможности повы- } \\
\text { шения квалификации и получение более вы- } \\
\text { годной должности }\end{array}$ \\
\hline
\end{tabular}

проводя критический анализ понятийного аппарата категории «стейкхолдеры», выделяет признаки их идентификации: уровень ответственности, степень влияния, степень близости, степень зависимости, уровень представительности [9]. Более того, автор высказывает мнение, что «...необходимость четкого понимания, кто такие стейкхолдеры, исследования вопросов их идентификации и классификации, анализа предъявляемых ими требований позволяет выделить такое самостоятельное направление аналитической работы, как стейкхолдер-анализ, который, в свою очередь, является одним из направлений бизнес-анализа» [там же].

Помимо сравнения элементов экономического анализа и бизнес-анализа по содержанию, автор считает целесообразным затронуть вопрос стандартизации анализа.
Международный институт бизнес-анализа (International institute of business analysis - IIBA) занимается стандартизацией и сертификацией образования в области аналитической деятельности [13]. В 2015 г. он выпустил уже третью редакцию стандарта по бизнес-анализу (Business analysis body of knowledge - BABOK v.3), который описывает области знаний, задачи, базовые компетенции, методики и точки зрения на бизнес-анализ.

Актуальность разработки и развития содержания документа обусловлена развитием профессиональной деятельности в области, связанной с анализом бизнеса компаний на разных этапах их деятельности.

Практика применения данного стандарта отражается в следующих аспектах:

- динамизм составления стандарта (развитие профессии формирует новые практики, 
Классификационные признаки субъектов экономического анализа и бизнес-анализа

\begin{tabular}{|c|c|c|}
\hline \multirow{10}{*}{$\begin{array}{l}\text { Субъекты } \\
\text { анализа }\end{array}$} & \multirow{4}{*}{$\begin{array}{l}\text { Экономический } \\
\text { анализ - пользо- } \\
\text { ватели информа- } \\
\text { ции }\end{array}$} & 1. Доступ к информационным потокам организации: \\
\hline & & $\begin{array}{l}\text { 1.1. Внешние - пользуются официальной информацией (инвесторы, бан- } \\
\text { ки, поставщики, налоговые органы, контрольно-ревизионное управление } \\
\text { Министерства финансов РФ, аудиторские фирмы, органы статистики, } \\
\text { Пенсионный фонд РФ, Фонд социального страхования РФ, поставщики, } \\
\text { покупатели, законодательные органы, юристы, пресса, профсоюзы). } \\
\text { 1.2. Внутренние - получают любую информацию, касающуюся дея- } \\
\text { тельности организации и перспектив ее развития (собственники, ру- } \\
\text { ководители, персонал) }\end{array}$ \\
\hline & & 2. Степень заинтересованности в результатах деятельности организации: \\
\hline & & $\begin{array}{l}\text { 2.1. Основные - непосредственно заинтересованы в результатах дея- } \\
\text { тельности организации (связаны с организацией участием в капитале, } \\
\text { долговыми и другими хозяйственными отношениями). } \\
\text { 2.2. Не основные - непосредственно не заинтересованы в результатах } \\
\text { деятельности организации (используют экономическую информацию } \\
\text { в профессиональных целях, защищают интересы первой группы поль- } \\
\text { зователей) }\end{array}$ \\
\hline & \multirow{6}{*}{$\begin{array}{l}\text { Бизнес-анализ - } \\
\text { стейкхолдеры } \\
\text { (заинтересован- } \\
\text { ные лица, заин- } \\
\text { тересованные } \\
\text { стороны) }[2 ; 5]\end{array}$} & 1. Степень зависимости от организации: \\
\hline & & $\begin{array}{l}\text { 1.1. «Ближние» стейкхолдеры (собственники, руководители, рабочие и } \\
\text { служащие компании, потребители ее продукции, партнеры по произ- } \\
\text { водственной кооперации, поставщики сырья). } \\
\text { 1.2. «Дальние», которых в меньшей степени затрагивает политика этой } \\
\text { организации (государственные органы, например) }\end{array}$ \\
\hline & & 2. Степень влияния на организацию: \\
\hline & & $\begin{array}{l}\text { 2.1. Основные стейкхолдеры (владельцы контрольного пакета акций, } \\
\text { федеральные и местные органы власти, банки, заказчики продукции, } \\
\text { ключевые поставщики и т. д.). } \\
\text { 2.2. Второстепенные, от которых компания зависит в меньшей степе- } \\
\text { ни (акционеры - миноритарии, незначительные партнеры, политиче- } \\
\text { ские партии и т. п.) }\end{array}$ \\
\hline & & 3. Степень участия в деятельности организации: \\
\hline & & $\begin{array}{l}\text { 3.1. Активные стейкхолдеры, реально участвующие в выработке поли- } \\
\text { тики компании и принятии управленческих решений (члены правле- } \\
\text { ния, совета директоров, топ-менеджеры). } \\
\text { 3.2. Пассивные - заинтересованы в работе этой компании, но не жела- } \\
\text { ют в ней непосредственно участвовать (значительная часть акционе- } \\
\text { ров, правительство, различные общественные движения и др.) }\end{array}$ \\
\hline
\end{tabular}

которые фиксируются в итоге в выпускаемых дополнениях, в новой версии стандарта);

- стандартизация должностных обязанностей штатного аналитика / договорных обязательств нанятого эксперта;

- разработка образовательных программ.

Относительно экономического анализа М. В. Мельник в одной из своих работ [15] поднимает вопрос о возможности его стандартизации. В этом ключе автор считает необходимым развести понятия «стандартизация», «унификация» и «типизация» в аналитической работе. Стандартизировать предлагается отдельные элементы осуществления аналитической работы и инструментария, который используется при анализе. В каче- стве объектов стандартизации выделяются следующие:

- алгоритмы показателей, обеспечение однозначности их названий, трактовок и методов расчёта;

- периодизация анализа;

- эталон критериев оценки, по которым даётся характеристика сложившегося экономического и финансового состояния;

- регламентация чёткости и последовательности действий;

- представление материалов, т. е. разработка специальных графиков, таблиц, матриц, системы взаимосвязанных коэффициентов, чтобы можно было четко и объективно сделать вывод о соответствующем качестве проведен- 
ной аналитической работы [там же]. Касаемо перехода стандартизации к собственно аналитической деятельности и соответствующих методик М. В. Мельник применяет термины: «унификация» и «типизация» видов аналитических работ. «Типизируя, можно создать унифицированные аналитические процессы, которые включают отдельные стандарты аналитической работы, и, маневрируя ими, ориентироваться на те цели и задачи, которые поставлены перед конкретным объектом» [там же].Д. А.Ендовицкий, например, высказываясь о понимании такого важного момента анализа любого объекта исследования, как методика, подчеркивает: «...инструктивный документ (имеющий статус корпоративного стандарта), в котором детально описывается механизм анализа объекта исследования с указанием всей возможной совокупности источников информации, организационного обеспечения работ, дается характеристика методам, приемам и процедурам анализа» [10]. Развитие вопросов стандартизации продолжает Е. Б. Герасимова в контексте обоснования возможного статуса стандарта экономического анализа: профессиональный стандарт или стандарт организации [7]. В этом ключе автор выражает мнение: «Решающую роль в развитии экономического анализа играет процесс упорядочения методик экономического анализа, выработки совокупности унифицированных подходов к анализу разных областей деятельности анализируемой организации» [8]. Упорядочивание должно быть подчинено принципам: удаление ненужного, рациональное размещение аналитических материалов, унификация правил, ответственность [там же].

Следует признать, на текущий момент времени констатируется недостаточность имеющейся нормативно-правовой базы для целей разработки системы стандартов экономического анализа; в системе профессиональных стандартов отсутствует стандарт аналитической деятельности, а описанные профессиональные квалификации лишь фрагментарно содержат некоторые аналитические процедуры. В качестве примера, подтверждающего данный факт, обратимся к профессиональному стандарту «Бухгалтер», утвержденному приказом Министерства труда и социальной защиты Российской Федерации № 103н от 21 февраля 2019 г.
Трудовая функция B/04.6 «Проведение финансового анализа, бюджетирование и управление денежными потоками» четвертая в численности обобщенной трудовой функции $B$ «Составление и представление бухгалтерской (финансовой) отчетности экономического субъекта», содержащая аналитическую деятельность. Среди необходимых аналитических умений выделены (фрагмент):

- определять объем работ по финансовому анализу, потребность в трудовых, финансовых и материально-технических ресурсах;

- разрабатывать внутренние организационно-распорядительные документы, регламентирующие порядок проведения работ по финансовому анализу;

- определять источники информации для проведения анализа финансового состояния экономического субъекта;

- планировать программы и сроки проведения финансового анализа экономического субъекта и осуществлять контроль их соблюдения, определять состав и формат аналитических отчетов;

- координировать взаимодействие работников экономического субъекта в процессе проведения финансового анализа;

- оценивать и анализировать финансовый потенциал, ликвидность и платежеспособность, финансовую устойчивость, прибыльность и рентабельность, инвестиционную привлекательность экономического субъекта;

- формировать обоснованные выводы по результатам информации, полученной в процессе проведения финансового анализа экономического субъекта.

Нетрудно заметить акцентирование внимания на аналитических знаниях и умениях в области исключительно финансового анализа.

В системе образования Российской Федерации с 2010 г. были внедрены образовательные стандарты третьего поколения, сформированные в рамках компетентностного подхода. Профессиональные компетенции, на основе которых формируются образовательные стандарты, выражают требования работодателей к профессиональным качествам выпускников образовательных организаций [14]. Утверждение профессиональных стандартов привело к изменению законодательства об образовании (Федеральный закон от 22 мая 2015 г. № 122-Ф3 «О внесении изме- 
нений в Трудовой кодекс Российской Федерации и статьи 11 и 73 Федерального закона “Об образовании в Российской Федерации”»), образовательные стандарты продолжают актуализироваться и в настоящее время (действующие ФГОС ВО 3+, разработка и утверждение ФГОС ВО 3++). Следует отметить факт признания, например, Федеральным государственным образовательным стандартом высшего образования уровень высшего образования бакалавриат направление подготовки 38.03.01. Экономика (утв. приказом Министерства образования и науки РФ от 12 ноября 2015 г. № 1327) аналитического вида деятельности как самостоятельного.

Соответствие компетенций выпускников вузов требованиям работодателей реализуется путем интеграции требований профессиональных стандартов в образовательные стандарты. Данный процесс не лишен противоречий и дискуссионных вопросов, требует упорядоченного и систематизированного подхода.

\section{Заключение}

Резюмируя разговор о профессиональной деятельности, обратимся к мнению В. И. Бариленко, который определяет сферу активности бизнес-аналитика в области экономического анализа, управленческого консультирования и организационного развития, моделирования и реинжиниринга бизнес-процессов, аналитического обоснования построения эффективных бизнес-моделей. С другой стороны, в современных условиях многообразие видов деятельности определяет выделение и развитие тематических направлений экономического анализа в системе экономической науки и практики: финансовый и управленческий анализ, инвестиционный и инновационный анализ, ресурсоориентированный анализ, экономико-социально-экологический анализ [11]. Самостоятельные направления экономического анализа интегрируют с другими направлениями функционирования экономических субъектов хозяйствования - управлением, информационным обеспечением, бухгалтерским учетом, организацией производства, научно-техническим развитием и т. п. [6]. Очевидно, ключевое слово, объясняющее различия между бизнес-анализом и экономическим анализом, - это слово «бизнес», последний может выступать одним из объектов экономического анализа, сам же бизнес-анализ становится тематическим направлением экономического анализа.

Подводя итог вышесказанному, сторонники бизнес-анализа говорят о развитии методологии экономического анализа как ее эволюции в соответствии с потребностями становления эффективной рыночной экономики нашей страны. Сторонники экономического анализа особенностью современного экономического анализа также констатируют существенное изменение его задач и функций [11]. Приверженцы бизнес-анализа признают эволюционность подходов к решению ряда аналитических задач не может рассматриваться как аргумент в пользу отрицания экономического анализа как важнейшего научного направления.

Бизнес-анализ, безусловно, нужно рассматривать как новое, актуальное направление в практике аналитической деятельности. Его можно рекомендовать как учебную дисциплину / образовательную программу в подготовке выпускников бакалавриата и/ или магистратуры для формирования соответствующих профессиональных компетенций. Опыт подготовки современных бизнес-аналитиков как работников в области делового анализа и информационно-аналитического обеспечения выбора оперативных, тактических и стратегических управленческих решений реализован кафедрой экономического анализа Финансового университета при Правительстве Российской Федерации по магистерской программе «Бизнес-аналитика».

Автор согласен с точкой зрения Д. А. Ендовицкого, Н. П. Любушина, Н. Э. Бабичевой, что алгоритм, объект и цель для ряда направлений экономического анализа идентичны, разница состоит в предмете исследования. Причем по некоторым дисциплинам эта разница практически не ощутима [там же]. Специфика бизнес-анализа в итоге определяется сферой практической деятельности.

\section{Конфликт интересов}

Авторы декларируют отсутствие явных и потенциальных конфликтов интересов, связанных с публикацией настоящей статьи. 


\section{Библиографический список}

1. Алексеева А. И. О методологическом обосновании науки и практики экономического анализа хозяйственной деятельности / А. И. Алексеева // Проблемы управления. - 2009. - №. 5. C. 74-80.

2. Бариленко В. И. Бизнес-анализ как важный вид консалтинговых услуг / В. И. Бариленко // Pесурсы. Информация. Снабжение. Конкуренция. 2012. - № 4. - C. 202-207.

3. Бариленко В. И. Бизнес-анализ как инструмент обеспечения устойчивого развития хозяйствующих субъектов / В. И. Бариленко // Учет. Анализ. Аудит. - 2014. - № 1. - С. 25-31.

4. Бариленко В. И. Особенности методологии бизнес-анализа / В. И. Бариленко // Экономика и управление: проблемы и решения. - 2014. № 3 (27). - C. 20-26.

5. Бариленко В. И. Роль бизнес-анализа в обосновании направлений инновационного развития / В. И. Бариленко // Инновационное развитие экономики. - 2012. - № 2 (8). - С. 124-131.

6. Барнгольц С. Б. Методология экономического анализа деятельности хозяйствующего субъекта / С. Б. Барнгольц, М. В. Мельник. - Москва : Финансы и статистика, 2003.

7. Герасимова Е. Б. Становление и перспективы развития стандартизации экономического анализа в России / Е. Б. Герасимова // Учет. Анализ. Аудит. - 2017. - № 1. - С. 55-61.

8. Герасимова Е. Б. Формирование парадигмы экономического анализа / Е. Б. Герасимова // Мир новой экономики. - 2016. - № 1. - С. 94-100.

9. Дуденков Д. А. Стейкхолдер-ориентированная модель компании в теории корпоративного управления / Д. А. Дуденков // Вестник Саратовского государственного социально-экономического университета. - 2014. - № 1. - С. 50-53.
10. Ендовицкий Д. А. Системный подход к экономическому анализу активов хозяйствующего субъекта / Д. А. Ендовицкий // Экономический анализ: теория и практика. - 2009. - № 15 (44). - С. 2-11.

11. Ендовицкий Д. А. Диалектика теоретико-методологических основ экономического анализа / Д. А. Ендовицкий, Н. П. Любушин, Н. Э. Бабичева // Экономический анализ: теория и практика. 2015. - № 20 (419). - С. 2-15.

12. Ендовицкий Д. А. Ресурсо-ориентированный экономический анализ : теория, методология, практика / Д. А. Ендовицкий, Н. П. Любушин, Н. Э. Бабичева // Экономический анализ: теория и практика. - 2013. - № 38 (341). - С. 2-8.

13. Иванова В. В. О международном стандарте бизнес-анализа / В. В. Иванова, Т. А. Лезина // Вестник Санкт-Петербургского университета. - 2011. № 4. - С. 107-115.

14. Крылов Д. Б. Профессиональные стандарты : проблемы применения и перспективы развития / Д. Б. Крылов, Ж. Г. Леонтьева // Вестник ВГУ. Серия: экономика и управление. - 2017. - № 3. - С. 91-94.

15. Мельник М. В. Оценка возможности стандартизации экономического анализа / М. В. Мельник // Транспортное дело России. - 2013. - № 4 (107). C. 187-190.

16. Михеев В. Н. К вопросу о методологии экономического анализа / В. Н. Михеев, И. Г. Бондаренко // ПСЭ. - 2012. - № 2. - С. 59-62.

17. Основы бизнес-анализа / под ред. В. И. Бариленко. - Москва : КНОРУС, 2014.

18. Пласкова Н. С. Развитие методологии экономического анализа / Н. С. Пласкова // Учет. Анализ. Аудит. - 2016. - № 1. - С. 50-57.

19. Шеремет А. Д. Комплексный анализ показателей устойчивого развития предприятия / А. Д. Шеремет // Экономический анализ: теория и практика. - 2014. - № 45 (396). - С. 2-10.
Кондрашова Надежда Викторовна, кандидат экономических наук, доцент кафедры экономического анализа и аудита, Воронежский государственный университет, Воронеж, Российская Федерация

E-mail: n.kondrashova@outlook.com

ORCID ID: 0000-0002-8818-0944
Поступила в редакциию 14.03.2020

Подписана в печать 14.04.2020 


\title{
Comparative characteristics of the contents of elements of economic analysis and business analysis
}

\author{
N. V. Kondrashova ${ }^{1 凶}$ \\ ${ }^{1}$ Voronezh State University, 1, University sq., 394018, Voronezh, Russian Federation
}

Cite as: Kondrashova, N.V. (2020). Comparative characteristics of the contents of elements of economic analysis and business analysis. Proceedings of Voronezh State University. Series: Economics and Management. 2, 45-54. (In Russ., abstract in Eng.) DOI: 10.17308/econ.2020.2/2900

Importance. A feature of modern economic analysis is a significant change in its tasks and functions. This is due to several reasons: transformation in the economic mechanism of enterprises; the diversity of activities highlights thematic areas of economic analysis; integration with other areas of the enterprise; interdisciplinarity. In recent years, business analysis has been actively developed. The listed reasons lead to the development of the methodology of economic analysis. The theory and practice of economic analysis is replenished with its directions, forms, methods, methods and techniques; areas of practical application of economic analysis expand.

Objectives. Author's study of the content of elements of economic analysis and business analysis: objective, subjects and objects, tools; comparing them to identify common or different traits. Issues of standardization of analysis as a process of scientific knowledge; as a practice of analyzing the economic activity of an enterprise; competency requirements in professional standards.

Methods. In the process of achieving this objective, the methods of scientific knowledge were used: dialectic; analysis and synthesis. The study is based on the study of relevant scientific and periodic economic literature.

Conclusions and Relevance. The conclusion is made on understanding business analysis as a separate thematic area of economic analysis and the type of analytical work. The specifics of business analysis is determined by the object, which is aimed at its practical activities. Business acts as an object of economic analysis, and business analysis itself becomes a thematic area of economic analysis. The most significant distinguishing feature of business analysis from traditional economic analysis is the change in the comparison base - the requirements of stakeholders.

Key words: methodology, directions of development of economic analysis, content of methodological characteristics, business analysis.

\section{Conflict of Interest}

The authors declare the absence of obvious and potential conflicts of interest related to the publication of this article.

\section{References}

1. Alekseeva, A. I. (2009) [On the methodological substantiation of science and practice of economic analysis of economic activity]. Problemy upravleniya. 5, 74-80. (In Russ.).

2. Barilenko, V. I. (2012) [Business analysis as an important type of consulting services]. Resursy. Informaciya. Snabzhenie. Konkurenciya. 4, 202-207. (In Russ.).

3. Barilenko, V. I. (2014) [Business analysis as a tool for ensuring sustainable development of business entities]. Uchet. Analiz. Audit. 1, 25-31. (In Russ.).

4. Barilenko, V. I. (2014) [Features of the business analysis methodology]. Ekonomika i upravlenie: problemy i resheniya. 3(27), 20-26. (In Russ.).
5. Barilenko, V. I. (2012) [The role of business analysis in substantiating the directions of innovative development]. Innovacionnoe razvitie ekonomiki. 2(8), 124-131. (In Russ.).

6. Barngolts, S. B. \& Melnik, M. V. (2003) [The methodology for the economic analysis of a business entity]. Moscow, Finansy i statistika Publ. (In Russ.).

7. Gerasimova, E. B. (2017) [The formation and the prospects of development of economic analysis standardization in Russia]. Uchet. Analiz. Audit. 1, 55-61. (In Russ.).

8. Gerasimova, E. B. (2016) [Forming economic analysis paradigm]. Mir novoj ekonomiki. 1, 94-100. (In Russ.). 
9. Dudenkov, D. A. (2014) [Stakeholder-oriented company model in corporate governance theory]. Vestnik Saratovskogo gosudarstvennogo social'no-ekonomicheskogo universiteta. 1, 50-53. (In Russ.).

10. Endovitsky, D. A. (2009) [A systems approach to the economic analysis of assets of a business entity]. Ekonomicheskii analiz: teoriya i praktika. 15 (44), 2-11 (In Russ.).

11. Endovitsky, D. A., Lyubushin, N. P. \& Babicheva, N. E. (2015) [The dialectics of theoretical and methodological background of economic analysis]. Ekonomicheskii analiz: teoriya i praktika. 20 (419), 2-15 (In Russ.).

12. Endovitsky, D. A., Lyubushin, N. P. \& Babicheva, N.E. (2013) [A resourceoriented economic analysis: theory, methodology, practice]. Ekonomicheskii analiz: teoriya i praktika. 38 (341), 2-8 (In Russ.).

13. Ivanova, V. V. \& Lezina, T. A. (2011) [About the international business analysis standard]. Vestnik Sankt-Peterburgskogo universiteta.4, 107-115.(In Russ.).
14. Krylov, D. B. \& Leontiev, Zh. G. (2017) [Professional standards: problems of application and development prospects]. Proceedings of Voronezh State University: Series: Economics and Management. 3, 9194. (In Russ.).

15. Melnik, M. V. (2013) [Assessment of the possibility of standardization of economic analysis]. Transportnoe delo Rossii. 4 (107), 187-190. (In Russ.).

16. Mikheev, V. N. \& Bondarenko, I. G. [To the question of the methodology of economic analysis]. PSE. 2, 59-62. (In Russ.).

17. Barilenko, V. I. (ed.) (2008) Business Analysis Basics. Moscow, KNORUS Publ. (In Russ.).

18. Plaskova, N. S. (2016) [The development of Economic Analysis Methodology]. Uchet. Analiz. Audit. 1, 50-57. (In Russ.).

19. Sheremet, A. D. (2014) [A complex analysis of sustainable development indicators of an enterprise]. Ekonomicheskii analiz: teoriya i praktika. 45 (396), 2-10 (In Russ.).
Nadezhda V. Kondrashova, Cand. Sci. (Econ.), Assoc. Prof., Department of Economic Analysis and Audit, Voronezh State University, Voronezh, Russian Federation

E-mail: n.kondrashova@outlook.com

ORCID ID: 0000-0002-8818-0944
Received 14.03.2020

Accepted 14.04.2020 